\title{
INVESTIGACIÓN
}

Recibido: 14/03/2021 --- Aceptado: 11/05/2021 --- Publicado: 07/06/2021

\section{LAS FAKE NEWS Y LOS PERIODISTAS DE LA GENERACIÓN Z. SOLUCIONES POST-MILLENNIAL CONTRA LA DESINFORMACIÓN}

\author{
Fake news and generation z journalists. Post-millennial solutions against \\ disinformation
}

\begin{abstract}
(D) $\mathbb{R}^{a}$ David García-Marín¹. Universidad Rey Juan Carlos. España. david.garciam@urjc.es
\end{abstract}

Investigación financiada por el Proyecto Internética: "Verdad y ética en las redes sociales. Percepciones e influencias educativas en jóvenes usuarios de Twitter, Instagram y Youtube". Proyecto $I+D+i$ subvencionado por el MCINN (PID 2019-104689RB-100). Fecha de inicio: 1 de junio 2020. Fecha de fin: 1 de junio 2023.

\section{Cómo citar el artículo:}

García-Marín, D. (2021). Las fake news y los periodistas de la generación z. Soluciones post-millennial contra la desinformación. Vivat Academia. Revista de Comunicación, 154, 37-63. http:// doi.org/10.15178/va.2021.154.e1324

http://www.vivatacademia.net/index.php/vivat/article/view/1324

\section{RESUMEN}

El fenómeno de la desinformación es uno de los asuntos más analizados en los últimos años en el ámbito de la investigación en comunicación. Sin embargo, aún no existe un gran conocimiento acerca de la percepción que sobre esta problemática tienen los jóvenes comunicadores, esenciales en la adopción de estrategias futuras para combatirla. Mediante la realización de 45 entrevistas en profundidad a periodistas de la Generación Z (media de edad: 24,14 años) complementadas con dos grupos de discusión y la aplicación de un cuestionario bajo la técnica del diferencial semántico (con tratamiento estadístico descriptivo e inferencial), esta investigación pretende conocer cuáles son las ideas hegemónicas de los nuevos periodistas sobre este fenómeno y cómo perciben sus posibles soluciones. Para los jóvenes periodistas, la solución del problema debe abordarse desde un tecnocentrismo integrador que combina el determinismo tecnológico con una perspectiva tradicionalista que continúa recurriendo a los viejos valores del periodismo para combatir los desórdenes

\footnotetext{
${ }^{1}$ David García-Marín: Profesor Ayudante Doctor en el Departamento de Ciencias de la Comunicación y Sociología de la Universidad Rey Juan Carlos (Madrid, España). Sus áreas de investigación se centran en la desinformación, el podcasting y el periodismo transmedia.
} 
informativos que proliferan en la actualidad. El periodismo de datos, que fusiona saberes y prácticas del periodismo tradicional con nuevos instrumentos tecnológicos, se percibe como una solución más eficaz que el fact-checking y la inteligencia artificial, a pesar de que estas dos últimas prácticas se consideran más rápidas para luchar contra la desinformación. En paralelo, estos profesionales de la comunicación ponen de relieve la necesidad de desarrollar la educación digital, mediática y crítica de la ciudadanía.

PALABRAS CLAVE: Desinformación - posverdad - fake news - periodismo de datos - fact-checking - inteligencia artificial - redes sociales - educación mediática Generación Z.

\section{ABSTRACT}

Disinformation has been one of the most analyzed issues in recent years in media studies. However, there is still a lack of research on young media professionals' perceptions about this problem. They are considered to be essential in the adoption of future strategies to tackle fake news. This research intends to discover the hegemonic ideas of new journalists on this problem and how they perceive its possible solutions. A total of 45 in-depth interviews to Generation $Z$ journalists (mean age: 24.14 years) were carried out, complemented with two focus groups and the application of a semantic differential scale, whose results were analyzed using both descriptive and inferential statistics. New journalists affirm the solution to the problem should be approached from an convergent technocentrism that combines technological determinism with a traditionalist perspective that resorts to the old values of journalism to combat the information disorders that proliferate today. Data journalism, which merges traditional journalistic practices with new technological tools, is perceived as a more effective solution than fact-checking and artificial intelligence, even though the latter two practices are considered as faster strategies to tackle disinformation. Likewise, new journalists highlight the need to develop digital, critical and media literacy for citizens.

KEY WORDS: Disinformation - post-truth - fake news - data journalism - factchecking - artificial intelligence - social media - media literacy - Generation Z.

\section{AS FAKE NEWS E OS JORNALISTAS DA GERAÇÃO Z. SOLUÇÕES PÓS MILLENNIAL CONTRA A DESINFORMAÇÃO}

\section{RESUMO}

O fenômeno da desinformação é um dos assuntos mais analisados nos últimos anos no âmbito da pesquisa na comunicação. Porém, ainda não existe um grande conhecimento sobre a percepção que esta problemática tem nos jovens comunicadores, essenciais na adoção de estratégias futuras para combatê-la. Mediante a realização de 
45 entrevistas aprofundadas a jornalistas da Geração Z (com uma média de idade de 24, 14 años) complementadas com dois grupos de discussão e aplicação de um questionário usando a técnica de diferencial semântico (com tratamento estatístico descritivo e inferencial) esta pesquisa pretende conhecer quais são as ideias hegemônicas dos novos jornalistas sobre este fenômeno e como percebem suas possíveis soluções. Para os jovens jornalistas, a solução do problema deve ser abordada desde um tecnocentrismo integrador que combina o determinismo tecnológico com uma perspectiva tradicionalista que continua usando os velhos valores do jornalismo para combater a desorganização informativa que proliferam na atualidade. $O$ jornalismo dos dados, que funde os saberes e práticas, se percebe como uma solução mais eficaz que o fast-checking e a inteligência artificial, apesar de que estas duas últimas práticas se consideram mais rápidas para lutar com a desinformação. Em paralelo estes profissionais da comunicação mostram a importância e a necessidade de desenvolver a educação digital, midiática e crítica da cidadania.

PALAVRAS CHAVE: Desinformação - pós verdade - fake news - jornalismo de dados-fact-checking - inteligência artificial - redes sociais - educação mediática Geração Z.

\section{INTRODUCCIÓN}

Aunque no es un fenómeno exclusivo de nuestro tiempo, la desinformación es uno de los asuntos de referencia en el ámbito de la investigación en comunicación desde el año 2016. Académicos y analistas como Graves (2016), Ball (2017), Davies (2016), D’Ancona (2017), Kakutani (2018), Thurston (2018), Fuller (2018), McIntyre (2018) o McNair (2018), entre otros, han centrado sus esfuerzos en comprender las causas, las motivaciones, los procesos de difusión y las implicaciones políticas, económicas, culturales y sociales de las noticias falsas, uno de los mayores desafíos que el sistema mediático y la sociedad en general deben afrontar en nuestros días. La mayoría de estas investigaciones se han focalizado en el análisis del discurso manipulador de los actores políticos en las sociedades occidentales (Donald Trump en Estados Unidos, el Brexit en Gran Bretaña y Jair Bolsonaro en Brasil se encuentran entre los casos más analizados); los mecanismos de difusión de tales contenidos en medios tradicionales y -sobre todo- en redes sociales; y en las maneras de combatir esta problemática con proyectos de verificación de la información y desde el ámbito educativo.

En los últimos meses, los estudios de caso relacionados con la Covid-19 han ocupado la mayor parte de la atención investigadora en este campo. Estos estudios pretenden describir e interpretar el fenómeno de las fake news vinculadas a la pandemia desde el análisis de la tipología de la desinformación (Brennen et ál., 2020; Salaverría et ál., 2020; García-Marín, 2020; Sánchez-Duarte y Magallón-Rosa, 2020), el papel de los profesionales de la información en este contexto de infodemia (AleixandreBenavent, Castelló-Cogollos y Valderrama-Zurián, 2020), los actores esenciales en la propagación de noticias falsas en las redes sociales (Pérez Dasilva, Meso-Ayerdi y Mendiguren-Galdospín, 2020), las imágenes falsas asociadas al virus (Andreu-Sánchez y Martín-Pascual, 2020), las fuentes informativas utilizadas por los usuarios para

Vivat Academia. Revista de Comunicación. 2021, nº 154, 37-63 
encontrar información sobre la enfermedad y sobre las medidas adoptadas por las instituciones (Elías y Catalán-Matamoros, 2020) y la conexión entre pandemia e infodemia (Peters, Jandric y McLaren, 2020; Gallotti et ál., 2020).

\subsection{Posverdad, desinformación y fake news}

En este contexto, los conceptos de posverdad, desinformación y fake news son representados como piezas del mismo puzzle. Aunque ya había sido utilizado anteriormente, el término posverdad fue popularizado por Keyes (2004) en su libro The Post-Truth Era: Dishonesty and Deception in Contemporary Life. Para este autor, la sociedad estadounidense habría entrado en una nueva era en la que las mentiras y las medias verdades dominan la vida diaria y, sobre todo, el ambiente político. De acuerdo con esta visión, varios serían los catalizadores del auge de este problema: “(1) el creciente fenómeno fan alrededor de ciertos personajes populares donde se valora más el entretenimiento que la integridad, (2) el postmodernismo académico que relativiza todas las nociones de verdad, y (3) el engaño derivado de las nuevas condiciones tecnológicas" (Keyes, 2004, p. 197). La posverdad se considera un nuevo régimen epistémico donde la respuesta emocional prevalece sobre la evidencia factual y el análisis razonado (Dahlgren, 2018). Se percibe como una nueva cultura que representa "una subordinación política de la realidad" (McIntyre, 2018, p. XIV).

Para estas voces, la posverdad designa una situación en la que un amplio volumen de personas vive en un espacio cognitivo que ha abandonado todo criterio de evidencia, "una realidad alternativa que es compartida por millones de ciudadanos" (Lewandowsky, Ecker y Cook, 2017, p. 360). Este diagnóstico parece tener graves implicaciones porque determina que la simple verificación de los hechos no sería suficiente para salir del régimen post-factual que estos autores dibujan (Woollacott, 2016).

La posverdad contribuye, por tanto, a crear ideas, imaginarios y representaciones sociales desde donde son posibles las fake news, noticias falsas que remiten a esos idearios afirmándolos o ampliándolos (Murolo, 2019). En su integración en estos mundos de posverdad, las fake news son percibidas como informaciones cuya falsedad puede ser verificada, creadas siempre con la intención de engañar (Allcott y Gentzkow, 2017; Guo y Vargo, 2018). Para McIntyre (2018), este término hace alusión a cualquier tipo de desinformación que es deliberadamente fabricada para parecer noticias verídicas, es decir construidas bajo una apariencia formalmente periodística. En esta línea, McNair (2018, p. 46) las define como "la invención o falsificación de hechos conocidos por fines comerciales o políticos que se presentan como noticias reales".

Sin embargo, la construcción del perímetro conceptual alrededor del término fake news no está exento de controversias. La más importante es el propósito de su producción. A diferencia de los autores anteriormente mencionados, para Silverman (2017) el término solo haría referencia a las falsas informaciones creadas por motivos económicos, excluyendo en su construcción teórica a los procesos de manipulación política. En la misma línea, Hunt (2016) defiende que, estrictamente hablando, las fake

Vivat Academia. Revista de Comunicación. 2021, n 154, 37-63 
García-Marín, D.

Las fake news y los periodistas de la generación $z$. Soluciones post-millennial contra la desinformación

news son informaciones falsas elaboradas desde cero para engañar a los receptores con el fin de maximizar el tráfico online y obtener beneficios económicos.

Las analogías y comparaciones entre el fenómeno de la desinformación y el ámbito médico ocupan un papel central en los relatos contemporáneos sobre las fake news. Un gran número de académicos ha sugerido que las noticias falsas son comparables a una peligrosa enfermedad infecciosa que se propaga por la sociedad a gran velocidad a través del contacto interpersonal (Heathman, 2018; Kucharkski, 2016), como si de un virus se tratara, desafiando al mundo de un modo nunca visto anteriormente (Rawlinson, 2017). Se considera, por tanto, que la desinformación tiene una naturaleza viral, representando una nueva forma de epidemia (Amrita, 2017; DiFranzo y GloriaGarcía, 2017).

Como consecuencia lógica de estas metáforas, académicos e intelectuales argumentan que existe una necesidad urgente de analizar la "epidemiología de las fake news" (Kucharski, 2016, p. 525) con el propósito de desarrollar una "diagnosis social apropiada" (Suiter, 2016, p. 26) detectando cuáles son los patógenos de la información maliciosa (Rubin, 2019) y probando "posibles curas" (Corner, 2017, p. 1104). La consecuencia de todo ello es una constante carrera por implementar "políticas de contención contra la desinformación" (Vosoughi, Roy y Aral, 2018, p. 1150) y descubrir una vacuna contra los contenidos falsos (Heathman, 2018) a fin de prevenir a los ciudadanos de ser contagiados por esta enfermedad, aludiendo para ello a la metáfora de la inoculación. Otros autores amplían esta visión cuando se refieren a las fake news como una plaga de las sociedades modernas (Amrita, 2017; Stelter, 2016) que se caracterizaría por su "enorme capacidad de resistencia" (D’Ancona, 2017, p. 67) frente a los constantes intentos de combatirla.

El enmarcado de las fake news como un fenómeno natural con sus propias dinámicas, desarrollos y procesos sirve no solo para destacar su propagación y diseminación, sino también para apuntar soluciones específicas para esta crisis. Estos posibles remedios incluyen, fundamentalmente, la confrontación del problema a través del control de los contenidos compartidos en las redes sociales (la erradicación de la enfermedad, bajo la metáfora vírica) y la inmunización de la sociedad (metáfora de la vacunación) por medio de programas de educación digital, mediática y/o informacional (Aparici y García-Marín, 2019).

\subsection{Justificación del estudio}

A pesar de todo este énfasis analítico e investigador alrededor de la desinformación, aún siguen siendo ciertamente escasos los estudios sobre las percepciones y las representaciones sociales que la ciudadanía (y más concretamente, colectivos claves como los profesionales de la información) tiene sobre esta problemática. Consideramos esencial conocer cómo el fenómeno de la desinformación es entendido e interpretado por voces significativas y actores relevantes en el campo de la comunicación y cómo tales percepciones e interpretaciones podrían determinar el presente y el futuro de la lucha contra este desafío. Resulta francamente difícil abordar las soluciones de un

Vivat Academia. Revista de Comunicación. 2021, nº 154, 37-63 
problema cuando no se conoce cuál es el entendimiento general de tal problemática. Se requiere, por consiguiente, la elaboración de un marco conceptual robusto antes de que el desafío de la posverdad pueda ser afrontado de forma efectiva (Higdon, 2020).

Es, por tanto, en el ámbito de las percepciones y las representaciones sociales acerca de la desinformación donde queremos situarnos. En este campo, destacan los estudios de Masip, Suau y Ruiz-Caballero (2020) acerca de las opiniones sobre los medios de comunicación y la desinformación, ideología y polarización en el sistema mediático español. Las investigaciones de Blanco-Herrero y Arcila-Calderón (2019) analizan las percepciones de los periodistas españoles sobre la utilidad de la deontología profesional para luchar contra las noticias falsas. Y en una línea similar, Brandtzaeg, Følstad y Chaparro-Domínguez (2018) centran sus estudios en cómo los periodistas perciben la utilidad del fact-checking y los servicios de verificación en la lucha contra la desinformación.

Sin menoscabar la relevancia de estos análisis, se observa un claro déficit investigador en el estudio de la percepción y los marcos de significado que sobre el fenómeno de la desinformación tienen los jóvenes profesionales de la comunicación, aquellos que están accediendo en este momento al mercado laboral, los que podríamos denominar "periodistas de la Generación Z" (los nacidos entre la mitad de la década de los 90 y finales de la década de 2010). Una de las escasas aproximaciones que podríamos ubicar en esta línea es la de Mendiguren, Pérez Dasilva, y Meso-Ayerdi (2020), que analiza las actitudes ante las fake news en estudiantes universitarios. Aunque coincidente en algunos términos con la nuestra, esta investigación presenta grandes diferencias con nuestro estudio porque, entre otros aspectos, se realizó no solo entre alumnos de grados relacionados con la comunicación, sino que la muestra estuvo compuesta también por estudiantes de otras áreas.

Consideramos que nuestro análisis resulta significativo porque está enfocado exclusivamente en graduados en áreas relacionadas con la Comunicación (grados en Periodismo, Comunicación Social, Doble Grado de Periodismo y Comunicación Audiovisual, etc.) que están dando sus primeros pasos en el campo profesional. Observamos que este colectivo resulta estratégico en el estudio de las representaciones sociales del fenómeno de la desinformación por varios motivos. Se trata de la primera generación que ha nacido y crecido con la web social, en un contexto eminentemente digital, por lo que presenta patrones y preferencias de aprendizaje diferentes, así como prácticas y preocupaciones sociales distintas a los individuos de generaciones precedentes (Seemiller y Grace, 2016). Esta generación se caracteriza también por mantener hábitos de consumo mediático propios y diferenciados (Turner, 2015). Asimismo, gran parte de sus estudios universitarios han coincidido con el periodo de eclosión de este fenómeno a partir del año 2016, por lo que disponen de una perspectiva situada a caballo entre el mundo académico en el que han estado integrados en los últimos años y el campo profesional al que, no sin dificultades, se están incorporando. Constituyen, en definitiva, la primera generación de periodistas que accede a las redacciones en un ecosistema mediático contaminado por los bulos y las fake news. Sin embargo, aún no existe un conocimiento extenso sobre sus

Vivat Academia. Revista de Comunicación. 2021, nº 154, 37-63 
características, necesidades, atributos y estilos de trabajo (Singh y Dangmei, 2016), a pesar de que esta generación de periodistas deberá liderar en los próximos años la lucha contra el desafío de la desinformación.

\section{OBJETIVOS Y MÉTODO}

Nuestro estudio pretende conocer cuáles son las representaciones sociales y las percepciones que estos jóvenes periodistas tienen acerca del fenómeno de la desinformación desde el punto de vista de sus posibles soluciones. Planteamos, por tanto, la siguiente pregunta de investigación: ¿Cuáles son los abordajes y estrategias que, según los periodistas de la Generación Z, deben implementarse para combatir esta problemática? En clara conexión con esta cuestión, los objetivos de nuestro trabajo se centran en determinar (1) cuáles son, a juicio de estos jóvenes periodistas, los ámbitos desde los que habría que desarrollar estas medidas y (2) cuáles son las propuestas concretas dominantes en el relato de este colectivo a la hora de establecer soluciones para este problema.

La investigación, de tipo exploratorio, se desarrolló en tres fases, vinculadas entre sí mediante articulación encadenada, de modo que los resultados de cada una de ellas sirvieron para construir los instrumentos de las fases inmediatamente posteriores (Callejo y Viedma, 2005).

- Fase 1. Se realizaron 45 entrevistas a graduados en carreras del sector de la Comunicación de 21 universidades españolas (Tabla 1). En el momento de realizar el trabajo de campo, estos profesionales eran, a su vez, estudiantes de dos másteres en comunicación digital y periodismo transmedia de la UNED, aspecto que facilitó el contacto con los investigadores. La media de edad de los sujetos participantes fue de 24,14 años. Las entrevistas fueron de tipo cualitativo, estructuradas bajo un guion cerrado (disponible en el siguiente enlace: https://cutt.ly/YzEzg8g) y en profundidad. Se llevaron a cabo durante los meses de marzo a julio de 2020 de forma telemática debido a la situación de pandemia por Covid-19. 
García-Marín, D.

Las fake news y los periodistas de la generación $z$. Soluciones post-millennial contra la desinformación

Tabla 1. Universidades de procedencia de los participantes en el estudio $(n=45)$

\begin{tabular}{|l|c|}
\hline \multicolumn{1}{|c|}{ Universidad } & $\begin{array}{c}\text { Número de } \\
\text { entrevistados }\end{array}$ \\
\hline Complutense & $8(17,77 \%)$ \\
\hline Málaga & $6(13,33 \%)$ \\
\hline Carlos III & $4(8,88 \%)$ \\
\hline Pompeu Fabra & $4(8,88 \%)$ \\
\hline Sevilla & $3(6,66 \%)$ \\
\hline Salamanca & $2(4,44 \%)$ \\
\hline Zaragoza & $2(4,44 \%)$ \\
\hline Rey Juan Carlos & $2(4,44 \%)$ \\
\hline Internacional de Catalunya & $2(4,44 \%)$ \\
\hline Valladolid & $1(2,22 \%)$ \\
\hline Oviedo & $1(2,22 \%)$ \\
\hline Almería & $1(2,22 \%)$ \\
\hline Granada & $1(2,22 \%)$ \\
\hline UOC & $1(2,22 \%)$ \\
\hline UNED & $1(2,22 \%)$ \\
\hline Deusto & $1(2,22 \%)$ \\
\hline Miguel Hernández (Elche) & $1(2,22 \%)$ \\
\hline Alicante & $1(2,22 \%)$ \\
\hline Barcelona & $1(2,22 \%)$ \\
\hline CEU San Pablo & $1(2,22 \%)$ \\
\hline La Laguna & $1(2,22 \%)$ \\
\hline
\end{tabular}

Fuente: Elaboración propia

- Fase 2. Con el fin de matizar y profundizar en los aspectos más relevantes procedentes de las entrevistas, se llevaron a cabo dos grupos de discusión con dos submuestras (8 participantes en cada uno de los grupos) obtenidas del conjunto de entrevistados en la fase anterior. Ambos grupos de discusión tuvieron lugar durante el mes de junio de 2020 también de forma telemática. En el proceso de selección de la muestra, se atendió tanto al criterio de homogeneidad o afinidad temática (todos los participantes eran profesionales de la comunicación pertenecientes a la Generación Z) como al de heterogeneidad, ya que los sujetos participantes procedían de universidades diferentes. El guion se fundamentó en los resultados obtenidos en las entrevistas estructuradas con el fin de aclarar ideas y descubrir matices en el discurso de los participantes. Se utilizó para indagar en el posicionamiento sobre las causas de la desinformación, el papel de los medios y de las plataformas digitales en esta problemática, los espacios donde se produce mayor distribución de fake news y las habilidades que deben adquirir los periodistas para combatirlas. Se dispuso de una guía flexible que permitió orientar de una forma efectiva su desarrollo (Tracy, 2020), posibilitando la producción de nuevos argumentos a partir de la interacción espontánea entre los participantes. La información resultante de la aplicación de ambos

Vivat Academia. Revista de Comunicación. 2021, nº 154, 37-63 


\section{desinformación}

instrumentos cualitativos (entrevistas y grupos de discusión) fue analizada con el apoyo del software NVivo v.12. En aras de proveer acceso abierto a los datos extraídos en nuestro trabajo de campo y facilitar su consulta, se ponen a disposición en el siguiente repositorio todos los fragmentos discursivos codificados procedentes de ambos instrumentos: https://cutt.ly/ezEjJwR. En el apartado de resultados, los datos extraídos de las entrevistas se presentan anonimizando a los participantes bajo la siguiente fórmula: ENT_XX donde XX es el número de entrevista. Para los grupos de discusión se utiliza el mismo procedimiento: GD_0X donde X es 1 o 2, dependiendo del grupo de discusión donde se produjo la afirmación referida.

- Fase 3 (de carácter cuantitativo). Tanto en las entrevistas como en los grupos de discusión, observamos que tres prácticas y/o herramientas periodísticas se aludían repetidamente como estrategias o aproximaciones útiles en la lucha contra la desinformación. Estas prácticas fueron el periodismo de datos, el factchecking y el uso de la inteligencia artificial. Con el fin de obtener un conocimiento más preciso de la percepción de los participantes sobre cada una de estas actividades, se aplicó la técnica del diferencial semántico. Con esta técnica es posible extraer los significados que determinados conceptos adquieren para los entrevistados a partir de su descomposición en atributos bipolares que los participantes deben evaluar sobre una escala (Corbetta, 2007) similar a las de tipo Likert. En nuestro estudio, dividimos cada uno de los conceptos a estudiar (periodismo de datos, fact-checking e inteligencia artificial) en un total de diez atributos estandarizados que funcionan, a su vez, como variables a medir. Son los siguientes: (1) eficacia, (2) sencillez, (3) coste económico, (4) universalidad (aplicabilidad a todo tipo de situaciones, contextos y temáticas), (5) carácter innovador (actualidad), (6) adaptabilidad a los cambios de la profesión (dinamismo), (7) rapidez, (8) neutralidad, (9) durabilidad y (10) experiencia requerida para su ejecución. Como se observa en la Figura 1, las cargas positivas de las variables se sitúan en los valores más bajos (hasta 1), mientras que las negativas se vinculan con los más elevados (hasta 5). Antes de proceder a su aplicación, se ejecutó una prueba de fiabilidad del cuestionario (test de Cronbach), cuyo valor fue de 0,703. Este valor, si bien no resulta excesivamente elevado, se puede considerar suficiente para aprobar la coherencia interna del instrumento (Frías-Navarro, 2019). En la Tabla 2, se muestran los valores del alfa de Cronbach en caso de suprimir cada una de las variables. Una vez validado, el cuestionario fue cumplimentado por los participantes. Seguidamente, se obtuvieron los estadísticos descriptivos para cada una de las prácticas periodísticas analizadas (periodismo de datos, fact-checking e inteligencia artificial), y se aplicó una prueba ANOVA (Análisis de la Varianza de un factor) y una prueba post hoc mediante test HSD Tukey para determinar la existencia de diferencias significativas en la valoración de cada una de las variables. Todas las operaciones estadísticas, tanto de tipo descriptivo como inferencial, se llevaron a cabo con el software especializado IBM SPSS v.26.

Vivat Academia. Revista de Comunicación. 2021, n 154, 37-63 
García-Marín, D.

Las fake news y los periodistas de la generación z. Soluciones post-millennial contra la desinformación

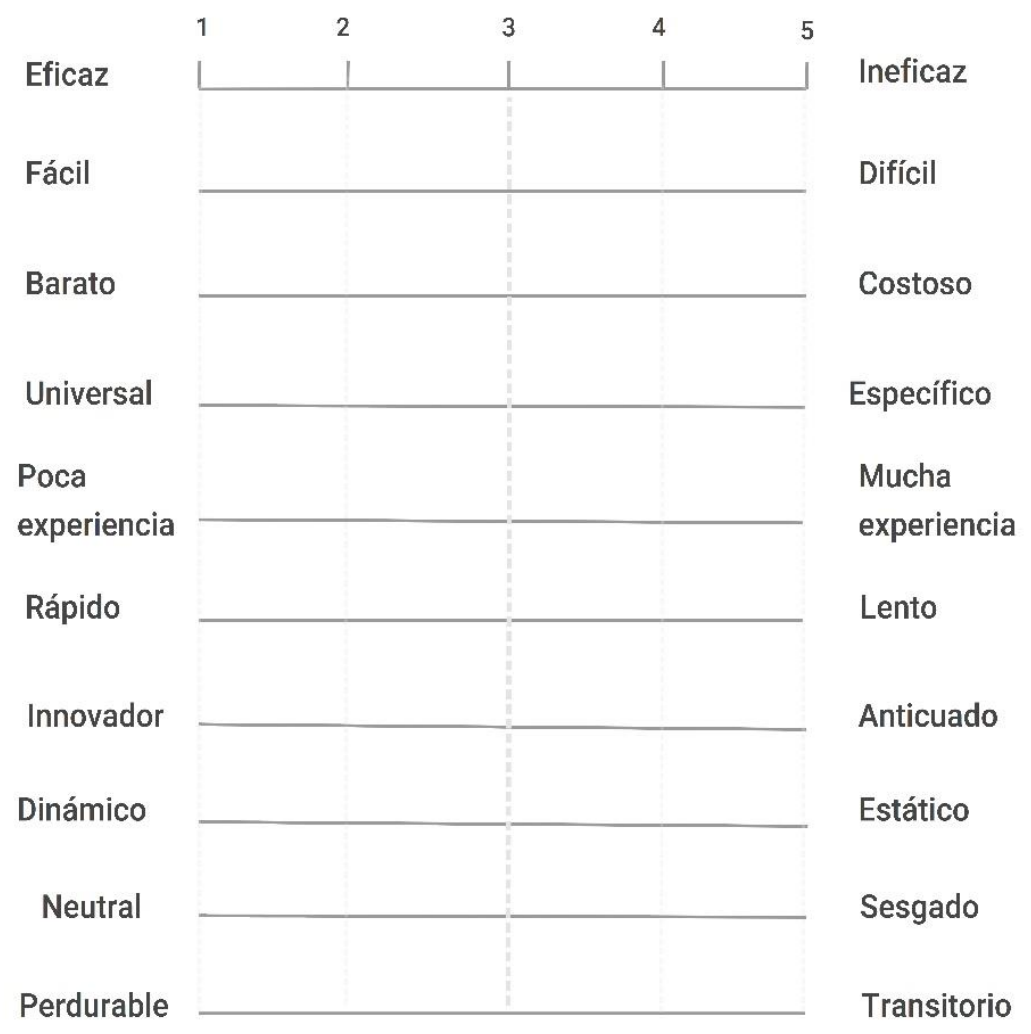

Figura 1. Diferencial semántico aplicado Fuente: elaboración propia

Tabla 2. Resultados de la prueba de Cronbach para comprobar la fiabilidad del cuestionario

\begin{tabular}{|l|c|l|c|}
\hline \multicolumn{1}{|c|}{ Variable } & \multicolumn{1}{|c|}{$\begin{array}{c}\text { Alfa de Cronbach } \\
\text { eliminando el } \\
\text { elemento }\end{array}$} & $\begin{array}{c}\text { Variable } \\
\text { eliminando el } \\
\text { elemento }\end{array}$ \\
\hline Eficacia & 0,675 & Rapidez & 0,679 \\
\hline Sencillez & 0,674 & Actualidad & 0,682 \\
\hline Coste & 0,700 & Dinamismo & 0,663 \\
\hline Universalidad & 0,700 & Neutralidad & 0,672 \\
\hline Experiencia & 0,684 & Durabilidad & 0,698 \\
\hline
\end{tabular}

Fuente: elaboración propia

\section{RESULTADOS}

\subsection{La lucha contra las fake news}

De acuerdo con el relato producido por los participantes en nuestro estudio, se distinguen tres ámbitos clave en la lucha contra la desinformación: (1) la acción de los medios de comunicación y los profesionales de la información, (2) las medidas 
implementadas por las plataformas digitales y (3) la educación mediática de toda la sociedad para identificar los contenidos falsos. A continuación, se analiza en profundidad cada uno de estos tres ámbitos.

\subsubsection{Soluciones desde el periodismo}

El periodismo tradicional se identifica como una institución esencial en la esfera pública democrática, por lo que el declive de su credibilidad está relacionado con el auge de las fake news (Dahlgren, 2018). A medida que el periodismo pierde relevancia como práctica profesional y principal gatekeeper en el establecimiento de la agenda informativa de las audiencias -a la vez que apuesta por un estándar profesional que privilegia la velocidad frente a la profundidad de las historias- se activa la atención de los públicos hacia fuentes de información de dudosa calidad (Elías y CatalánMatamoros, 2020). A esto se añade un evidente problema de transparencia que torpedea la confianza de los ciudadanos en la práctica periodística (Sambrook, 2018).

Estos mismos discursos críticos hacia la profesión son asumidos por los profesionales de la Generación Z, para quienes el periodismo tiene la misión de proteger la democracia buscando la verdad y denunciando la mentira, sobre todo de aquellos que ostentan algún tipo de poder. Defienden que el ejercicio del periodismo bien ejecutado equipa a los ciudadanos con las herramientas suficientes para controlar a aquellos que ejercen el poder y evita que las audiencias busquen información en fuentes no creíbles.

Por este motivo, abogan por una mayor calidad, una apuesta por el rigor informativo y un refuerzo de los principios éticos de la profesión. Para estos nuevos periodistas, "los medios de comunicación deben hacer una apuesta por los trabajos de calidad que no caigan en la desinformación de ninguna de las maneras" (ENT_12), erigirse en abanderados "de la pulcritud antes que la primicia" (GD_02) y ofrecer una información correctamente "contextualizada y verificada" (ENT_31) para no contribuir "a esta verbena de falsas informaciones y sensacionalismo en la que vivimos" (GD_02).

Una de las prácticas periodísticas que censuran es el clickbait, presente incluso en los periódicos de mayor calidad (García-Serrano, Romero-Rodríguez y Hernando-Gómez, 2019): “Deberían hacer autocrítica y huir del contenido realizado únicamente para viralizarse, del clickbait" (ENT_42). Asimismo, solicitan la reformulación de los esquemas tradicionales de comunicación entre medios y audiencias con el fin de recuperar su confianza. En este sentido, sería fundamental la adopción de un modelo de comunicación más bidireccional, propio de las estructuras comunicativas de la Red, donde "los medios escuchen a la audiencia, dialoguen con ella y admitan y corrijan errores" (ENT_05).

La conexión entre medios y usuarios debería reforzarse también con el papel de las instituciones periodísticas como catalizadoras de la educación mediática de las audiencias. La labor pedagógica desde los medios en un contexto gobernado por la

Vivat Academia. Revista de Comunicación. 2021, nº 154, 37-63 
saturación de información y la creciente circulación de contenidos maliciosos se considera una interesante vía a explorar con el fin de "alertar de la circulación de información falsa explicando el porqué de su falsedad" (ENT_24) y "divulgar cómo han llegado a descubrir que un contenido se trataba de una información falsa" (ENT_32). Los medios deberían utilizar su posición de poder para formar a la población sobre cómo consumir información veraz diferenciando "los preceptos de rigor que debe tener una pieza periodística" (ENT_33).

Para ello, defienden la existencia de espacios o secciones específicas donde "se muestre cómo identificar estos bulos" (ENT_27). No existe, sin embargo, una posición unitaria acerca de la necesidad de incorporar departamentos propios de verificación en los medios tradicionales. Por un lado, el fact-checking integrado en las redacciones se considera una práctica positiva "para verificar las informaciones desde los medios, permitiendo así al usuario validar cualquier cosa que considere sospechosa" (ENT_19). Por otro, se defiende la existencia de una diferenciación entre medios de comunicación y plataformas de verificación: "No creo que deban existir dentro de los medios tradicionales porque ya todos sabemos a quién se debe cada uno" (ENT_37). Esta posición resulta coherente con los resultados obtenidos en la tercera fase de nuestra investigación -cuyos datos expondremos más adelante- donde observamos que el factchecking es percibido como una práctica menos neutral que otros instrumentos (la inteligencia artificial) utilizados para combatir las fake news.

Asimismo, los periodistas de la Generación $\mathrm{Z}$ defienden un mayor pluralismo en las líneas editoriales de los medios para romper sus sesgos ideológicos y sacar de una "zona de confort a sus usuarios para evitar que éstos terminen convirtiéndose en perezosos mentales" (GD_01).

El trabajo a desarrollar desde los medios de comunicación incluye la propia formación de los periodistas. A partir del discurso producido por los participantes en nuestro estudio, se apuntan algunas claves sobre cuáles deben ser las competencias a potenciar desde dentro del sistema universitario en los grados del área de Comunicación ofertados en nuestro país. En general, los periodistas de la Generación $\mathrm{Z}$ adoptan en este terreno una aproximación tecnocéntrica que les lleva a definir las competencias tecnológicas y digitales como las más importantes a la hora de hacer frente a la desinformación. En su discurso, resulta imprescindible "la adquisición de competencias digitales y herramientas actuales específicas relativas a la verificación de hechos y datos" (ENT_01) porque para determinar si un contenido que circula en las redes es o no fiable "debemos conocer las dinámicas sobre cómo se están extendiendo las noticias falsas" (ENT_06).

Al vincular la producción y distribución de desinformación con las redes sociales y los entornos digitales en general, nuestros entrevistados afirman que es esencial que los comunicadores del siglo XXI conozcan su lenguaje y sus formas de actuación, así como ser rápidos "en investigar el origen de la noticia, por lo que debemos comprender perfectamente cómo funcionan los buscadores" (ENT_23). En este sentido, demandan una mayor formación técnica para aprender "las herramientas

Vivat Academia. Revista de Comunicación. 2021, nº 154, 37-63 
necesarias para saber identificar los patrones de producción y circulación de una información falsa" (ENT_09) o para "dominar instrumentos de monitorización de datos" (ENT_16).

Las competencias digitales anteriormente descritas deben añadirse a las aptitudes y valores que el periodismo tradicional consagró desde su nacimiento, sobre todo aquellos que se centran en una correcta gestión de las fuentes de información. La verificación de las fuentes se percibe como una competencia crítica para la lucha contra los desórdenes informativos, de forma que "cuando un periodista recibe una información, sea cual sea la fuente, deberá ser debidamente tratada antes de trabajar con ella" (ENT_25). El papel del periodista debe ser activo y exhaustivo en la comprobación de los datos, por lo que resultaría necesaria una cierta "formación en fact-checking, capacidad analítica y de investigación" (ENT_20) para no limitarse a ser "meros altavoces del poder" (ENT_32). Afirman que "el nuevo periodismo debe salir del viejo periodismo y tomarse el tiempo que haga falta para contrastar las informaciones y cuidar las fuentes" (ENT_19). En esta línea, valoran la capacidad para integrar en los trabajos periodísticos diferentes visiones de la realidad utilizando una variedad de voces, con el fin de "cubrir todos los ángulos de esa información" (ENT_04).

Las percepciones sobre la formación que actualmente están ofreciendo las universidades a los futuros profesionales como actores esenciales en contra de la desinformación será analizada de manera más profunda en el apartado dedicado al ámbito educativo.

\subsubsection{La vía tecnológica. El papel de las plataformas digitales}

La aproximación tecnológica al fenómeno de la desinformación se substancia también en el papel central que los periodistas de la Generación Z otorgan a las plataformas digitales en la lucha contra las fake news. Para los jóvenes periodistas entrevistados, las plataformas digitales no deben mantenerse al margen de lo que se publica, sino que deben controlar la información propagada por sus usuarios. La detección, el etiquetado y la eliminación de bulos, la lucha contra los bots que distribuyen de forma automatizada información falsa en las redes y una mayor visibilidad y facilidad de acceso a las fuentes de calidad -en detrimento de los espacios de la Red que difunden contenidos falsos o sesgados- son los principales aspectos señalados por los entrevistados.

El discurso más común sobre el papel de las plataformas digitales defiende la adopción de medidas para eliminar la información cuya falsedad ha quedado demostrada. La censura de estos contenidos sería una medida a aplicar por parte de las grandes compañías tecnológicas como Facebook, Twitter, Google, etc., que deberían implementar "mecanismos de verificación más potentes que permitan suprimir estos mensajes desde el inicio, antes de que se viralicen" (ENT_36). Históricamente, las fake news han servido como catalizador para la expansión de miedo y ansiedad, que funcionan como activadores de pánico moral y violencia (Schinkel,

Vivat Academia. Revista de Comunicación. 2021, nº 154, 37-63 
2008). Es por ello que, a juicio de los sujetos entrevistados, esta censura previa tendría que ser más contundente "sobre aquellos que contribuyen a fomentar discursos de odio hacia los colectivos más desfavorecidos" (ENT_07).

Otro mecanismo de censura asumido es el bloqueo de cuentas de aquellos actores especialmente activos en la difusión de fake news: “Ya que tienen la potestad de regular su funcionamiento interno, deberían bloquear cuentas falsas o eliminar posts que contengan información maliciosa" (ENT_10). El etiquetado de la información falsa "mediante notificaciones emergentes como hace Facebook o utilizando modelos similares" (ENT_24) o la aplicación de "mecanismos para dificultar la propagación de contenidos falsos" (ENT_28) son otras estrategias que, aunque en menor medida, fueron mencionadas durante el trabajo de campo. La lucha contra los bots se debería articular desde "la verificación de la identidad de los perfiles" (ENT_17), a la vez que estas plataformas deben privilegiar el acceso a fuentes fiables y "evitar dirigir al usuario a las poco veraces" (ENT_13).

La adopción de estas medidas no está exenta, sin embargo, de dificultades y desafíos éticos que podrían poner en peligro la libertad de expresión. Varios de los periodistas entrevistados no están de acuerdo con las medidas de censura de contenidos ni con el bloqueo de cuentas porque "[las plataformas] se pueden extralimitar en sus competencias, como ya se ha demostrado en algunos casos en los que se censuran determinados posts y otros similares no" (ENT_06), por lo que "deberían tener mecanismos de verificación de los emisores, pero nunca de censura hacia sus mensajes" (ENT_19).

\subsubsection{Formar a la ciudadanía en la era de la desinformación}

El último bloque de soluciones aportadas por los jóvenes periodistas se sitúa en el ámbito educativo, a partir de tres aproximaciones claramente diferenciadas: (1) la educación digital, (2) la educación mediática y (3) la educación crítica. Analizamos a continuación cada una de ellas.

1. Educación digital. Esta primera aproximación al papel de la formación ahonda en el discurso tecnológico. Si fundamentalmente el problema de la desinformación es percibido como una consecuencia de la popularización de las redes sociales y los entornos digitales de comunicación que favorecen la producción y difusión de noticias falsas, la educación digital "de toda la ciudadanía" (GD_02) se erige como uno de los principales factores en la lucha contra los procesos desinformativos. Para los profesionales de la Generación Z, el medio digital constituye el terreno más fértil para la proliferación de informaciones maliciosas. La irrupción de las nuevas tecnologías de la información y la comunicación en nuestra sociedad habría traído consigo la creación de una nueva necesidad: la alfabetización digital como factor de desarrollo humano e inclusión a fin de reducir o evitar acentuar la brecha digital, que perciben como un "reflejo de la desigualdad social existente fuera del universo virtual" (ENT_01). Son conscientes de que la mayoría de los

Vivat Academia. Revista de Comunicación. 2021, n 154, 37-63 
ciudadanos no poseen las competencias necesarias para identificar la información falsa, por lo que deberían adquirir conocimientos técnicos porque, al igual que se utiliza la tecnología para su difusión, "también hay más herramientas que nunca para comprobar si algo es verdad" (ENT_13). Estas acciones de alfabetización digital deben incluir a toda la sociedad, independientemente de la edad, ya que el hecho de "no poseer conocimientos tecnológicos básicos limita la calidad de la dieta informativa de las audiencias" (ENT_05).

2. Educación mediática. Los periodistas de la Generación Z entienden esta competencia de forma diferente a las habilidades digitales. La definen como aquellas aptitudes informacionales que la ciudadanía debería adoptar para conocer de forma básica los estándares de producción y difusión de noticias de calidad, así como la composición estructural de la información legítima a fin de diferenciarla de los desórdenes informativos. A estas competencias se uniría la capacidad de gestión de la sobrecarga informativa que caracteriza a la sociedad digital. Los jóvenes periodistas observan que una sociedad democrática puede mitigar la influencia negativa de las fake news si su ciudadanía recibe formación sobre los criterios y las prácticas que constituyen la labor periodística. Para ello, las instituciones educativas deberían enseñar a discernir entre opiniones y hechos y contribuir a un consumo responsable y diverso de fuentes informativas. Abogan por la creación de un currículum educativo que incluya "medidas para hacer conscientes a los jóvenes de la cantidad de información que tienen en el bolsillo" (ENT_24), cómo usarla para ser mejores ciudadanos y el inmenso daño que pueden hacerse incluso a sí mismos si no la utilizan correctamente. Sería fundamental, por tanto, "enseñar desde los centros educativos, a contrastar la información desde que son pequeños, y a no quedarse con lo primero que escuchan, leen $\mathrm{u}$ observan en la televisión y las redes" (ENT_29), así como "educar en saber leer las noticias, contrastar, discernir y valorar" (ENT_39).

3. Educación crítica. Los participantes en el estudio defienden que si se desea que la información genere conocimiento y que la educación digital no tenga un carácter puramente instrumental quedando reducida a la adquisición de competencias técnicas, habría que facilitar el acceso a una formación que ponga en valor el pensamiento crítico. De lo contrario, aunque se reciba una instrucción adecuada en materia tecnológica, difícilmente se aprovecharía todo su potencial pedagógico. Se percibe que, poniendo en juego sus propios sesgos cognitivos, el ciudadano también participa de los procesos de desinformación. Para combatirlos, debería "adoptar una posición de sujeto crítico y no sólo de consumidor pasivo de información que comparte interesada e irresponsablemente contenidos de dudosa procedencia" (ENT_41). Los jóvenes periodistas entrevistados demandan una ciudadanía exigente con el contenido que consume y que deje de sentirse atraída por "medios que nos han provisto de informaciones falsas" (ENT_12) a fin de cuestionar la información a la que

Vivat Academia. Revista de Comunicación. 2021, nº 154, 37-63 
accede y "tener siempre pensamiento crítico para preguntarse: ¿es esto cierto?" (ENT_04). En este sentido, los ciudadanos deben ser conscientes de los intereses que están detrás de la produccion de cada información. Desde su punto de vista, empoderar a la ciudadanía con esta actitud crítica equivaldría a generar una sociedad menos desinformada.

A juicio de los entrevistados, la educación digital, mediática y crítica se deben proveer desde las más tempranas edades mediante la "incorporación de asignaturas o programas específicos en los currículos" (GD_02). Esta opinión contrasta con la falta de acciones formativas de este tipo en todos los niveles educativos. La opinión general es que ni colegios, ni institutos, ni universidades tratan el asunto de la desinformación en España. Afirman que más allá de incluir conceptualizaciones teóricas sobre posverdad o desinformación, no existe ninguna asignatura a lo largo de los grados en el ámbito de la Comunicación que aborde estos asuntos en un sentido amplio, ahonde en sus causas y consecuencias y profundice en la verificación de hechos y datos y en la enseñanza de otras herramientas específicas para combatir las fake news.

Desde los centros educativos, esta problemática es tratada a grandes rasgos mediante explicaciones superficiales sobre su definición y el análisis de su importancia para la profesión, pero sin ofrecer abordajes profundos y prácticos sobre el problema: "En el instituto, la formación en este terreno fue totalmente inexistente; y en la universidad hablamos alguna vez del asunto, pero nunca con una formación fundamentada y organizada" (ENT_25).

Los periodistas de la Generación $Z$ perciben que en los grados del área de Comunicación, la desinformación se aborda de manera superficial y en todo tipo de asignaturas, tanto de enfoque teórico como práctico y metodológico. Algunas de las materias señaladas por los sujetos entrevistados fueron Estructura y Poder de la Información, Periodismo Digital, Metodologías de la Investigación Periodística, Deontología Periodística, Opinión Pública, Redacción Periodística, Sociología y Postproducción Audiovisual. Se percibe, por tanto, que el tratamiento de esta problemática no se establece en una asignatura concreta, sino que se vincula con la acción voluntarista de profesores interesados en el tema y motivados por el análisis de los procesos desinformativos en las aulas.

Es, sin embargo, en el ámbito laboral donde encuentran mayores oportunidades para la formación en esta materia. Nuestros entrevistados afirman haber participado en talleres prácticos de corta duración organizados por sus empresas e impartidos habitualmente por compañías tecnológicas que ofrecen formación instrumental en el uso de software propio para abordar de forma muy concreta determinadas necesidades periodísticas, tales como la verificación de fuentes, la detección de imágenes y vídeos falsos y la identificación de fake news en redes sociales: "La única vez que recuerdo haber recibido información al respecto fue durante mi primera etapa de la beca EFE-LaCaixa, cuando desde Google nos ofrecieron una formación sobre verificación online y herramientas contra la desinformación” (ENT_33). 
Esta formación específica usualmente se centra en la adquisición de competencias técnicas basadas en el fact-checking, el periodismo de datos y la utilización de herramientas automáticas de inteligencia artificial para detectar falsas informaciones o fuentes maliciosas. Como señalamos anteriormente, estas tres prácticas periodísticas fueron especialmente destacadas en el discurso de los participantes en nuestra investigación. Es por ello que la última parte de nuestro estudio analiza en profundidad la percepciones alrededor de estos tres instrumentos como herramientas útiles en la lucha contra la desinformación.

\subsection{Fact-checking, periodismo de datos e inteligencia artificial}

Mediante la aplicación de la técnica del diferencial semántico, los sujetos encuestados valoraron el fact-checking como una estrategia marcadamente moderna y actual $(M=1,66)$, eficaz $(M=1,87)$, dinámica y adaptable a los futuros cambios de la profesión periodística $(M=1,97)$ (ver Tabla 3 y Figura 2$)$. Las cargas menos positivas vinculadas con esta herramienta se sitúan en la experiencia necesaria para su ejecución $(M=3,07)$. Además, se percibe como un instrumento con una moderada capacidad para operar en diversas circunstancias y temáticas $(M=2,74)$, y para dar una respuesta rápida ante la proliferación de fake news $(2,69)$.

El periodismo de datos logra valores positivos en términos de eficacia $(M=1,82)$, durabilidad en el tiempo (percepción de este instrumento no como una moda pasajera) $(M=2,18)$ y capacidad de adaptación ante los posibles cambios en la profesión $(M=2,35)$. Sus debilidades estarían en la lentitud a la hora de realizar sus procesos $(M=3,78)$, la experiencia requerida para su ejecución $(M=3,63)$ y su complejidad $(M=3,16)$.

Dada su novedad y perspectivas de futuro en su aplicación a la profesión, resulta especialmente interesante la valoración de los nuevos periodistas sobre los instrumentos de inteligencia artificial. En primer término, estas herramientas permiten determinar la credibilidad de las fuentes informativas a partir de su análisis reputacional, a la vez que ofrecen una poderosa respuesta para identificar perfiles falsos en redes sociales (bots) capaces de desarrollar campañas contra la estabilidad de ciertos países y crear falsas tendencias de apoyo a determinadas corrientes ideológicas y figuras políticas. El otro gran campo de batalla es la detección de contenidos desinformativos mediante el uso de la lingüística computacional (utilizando modelos semánticos y sintácticos), y de métodos no lingüísticos para detectar las posibles manipulaciones presentes en las imágenes (vídeos o fotografías).

Estos desarrollos han sido implementados en los últimos años por las grandes plataformas tecnológicas en su lucha contra los contenidos desinformativos. Facebook, además de contratar a 5000 trabajadores para identificar mensajes ofensivos, también ha invertido en instrumentos de inteligencia artificial y aprendizaje automático para detectar contenidos falsos, sobre todo aquellos que proceden de la propaganda computacional (Iosifidis y Nicoli, 2020; Wooley, 2020), como respuesta a la crisis

Vivat Academia. Revista de Comunicación. 2021, nº 154, 37-63 
Las fake news y los periodistas de la generación $z$. Soluciones post-millennial contra la desinformación

generada por Cambridge Analytica. Uno de los motores algorítmicos incorporados al funcionamiento de la plataforma fue Deeptext, un ingenio basado en lingüística computacional capaz de leer y comprender contenido textual procedente de varios miles de publicaciones por segundo en más de 20 idiomas distintos.

En este contexto, la inteligencia artificial es percibida por los participantes en nuestro estudio como una herramienta muy innovadora, actual $(M=1,30)$, eficaz $(M=2,05)$ y con gran perspectiva de futuro $(M=2,10)$. Comparte con el periodismo de datos la necesidad de una considerable experiencia para su manejo $(M=3,89)$ y la falta de sencillez en su aplicación $(M=3,18)$, a la vez que presenta cargas negativas moderadas en cuanto al coste económico para su implantación $(M=3,64)$.

Tabla 3. Valoraciones medias de cada una de las variables analizadas para el factchecking, el periodismo de datos y la inteligencia artificial. Se marcan en verde y rojo, respectivamente, los mejores y peores valores para cada variable en cada uno de los instrumentos; así como los mejores y peores valores de la media general de cada variable y su desviación típica (D.T.)

\begin{tabular}{|l|c|c|c|c|c|}
\hline \multicolumn{1}{|c|}{ Variable } & $\begin{array}{c}\text { Fact- } \\
\text { checking }\end{array}$ & $\begin{array}{c}\text { Periodismo } \\
\text { de datos }\end{array}$ & $\begin{array}{c}\text { Inteligencia } \\
\text { artificial }\end{array}$ & $\begin{array}{c}\text { Media } \\
\text { general de la } \\
\text { variable }\end{array}$ & $\begin{array}{c}\text { D.T. de la } \\
\text { variable }\end{array}$ \\
\hline Eficacia & 1,87 & $\mathbf{1 , 8 2}$ & 2,05 & 1,91 & 0,9 \\
\hline Sencillez & 2,56 & 3,16 & 3,18 & 2,96 & 1,24 \\
\hline Coste & 2,42 & 3,10 & 3,64 & 3,06 & 1,23 \\
\hline Universalid. & 2,74 & 2,53 & 2,71 & 2,66 & 1,23 \\
\hline Experiencia & 3,07 & 3,63 & 3,89 & 3,52 & 1,13 \\
\hline Rapidez & 2,69 & 3,78 & 2,23 & 2,88 & 1,27 \\
\hline Actualidad & 1,66 & 2,53 & 1,30 & 1,83 & 1,04 \\
\hline Dinamismo & 1,97 & 2,36 & 2,10 & 2,14 & 1,11 \\
\hline Neutralidad & 2,41 & 2,68 & 2,17 & 2,42 & 1,08 \\
\hline Durabilidad & 2,56 & 2,18 & 2,10 & 2,28 & 1,15 \\
\hline $\begin{array}{c}\text { Media } \\
\text { general del } \\
\text { instrumento }\end{array}$ & 2,39 & 2,77 & 2,53 & & \\
\hline $\begin{array}{c}\text { D.T. del } \\
\text { instrumento }\end{array}$ & 0,39 & 0,60 & 0,74 & & \\
\hline
\end{tabular}

Fuente: elaboración propia

En términos de eficacia, las tres herramientas presentan cargas positivas con valores más próximos al polo positivo de la variable (totalmente eficaz) que al negativo (totalmente ineficaz). El análisis de esta variable determina que la herramienta mejor valorada es el periodismo de datos $(M=1,82)$, que logra valores muy similares a los conseguidos por el fact-checking $(M=1,87)$. La inteligencia artificial se percibe como el instrumento menos eficaz $(M=2,05)$, aunque adquiere también valores moderadamente positivos, situados por debajo del valor medio de la escala utilizada. 
García-Marín, D.

Las fake news y los periodistas de la generación z. Soluciones post-millennial contra la desinformación

Por contra, los tres instrumentos son considerados ciertamente complejos de aplicar, siendo la inteligencia artificial la que presenta las peores valoraciones para esta variable $(M=3,18)$, seguida del periodismo de datos $(M=3,16)$. El fact-checking se percibe como el instrumento con una menor complejidad en cuanto a su aplicación $(M=2,56)$. Esta última herramienta se considera bastante más barata de implementar $(M=2,42)$ que las otras dos (el periodismo de datos presenta una valoración media de 3,10, mientras que la inteligencia artificial se dispara hasta el 3,64). Sin embargo, la inteligencia artificial se valora como la herramienta más rápida para hacer frente a la desinformación $(M=2,23)$, marcando una gran distancia con respecto al periodismo de datos $(M=3,78)$. Los tres instrumentos consiguen valores moderadamente positivos en términos de neutralidad. La inteligencia artificial se percibe como el instrumento con menos sesgos $(M=2,17)$ frente al fact-checking $(M=2,41)$ y el periodismo de datos $(M=2,68)$. En cuanto a la variable relativa a la innovación, la inteligencia artificial $(M=1,30)$ y el fact-checking $(M=1,66)$ consiguen los mejores promedios, siendo el periodismo de datos el conjunto de técnicas consideradas bajo un prisma más clásico o tradicional $(M=2,53)$.

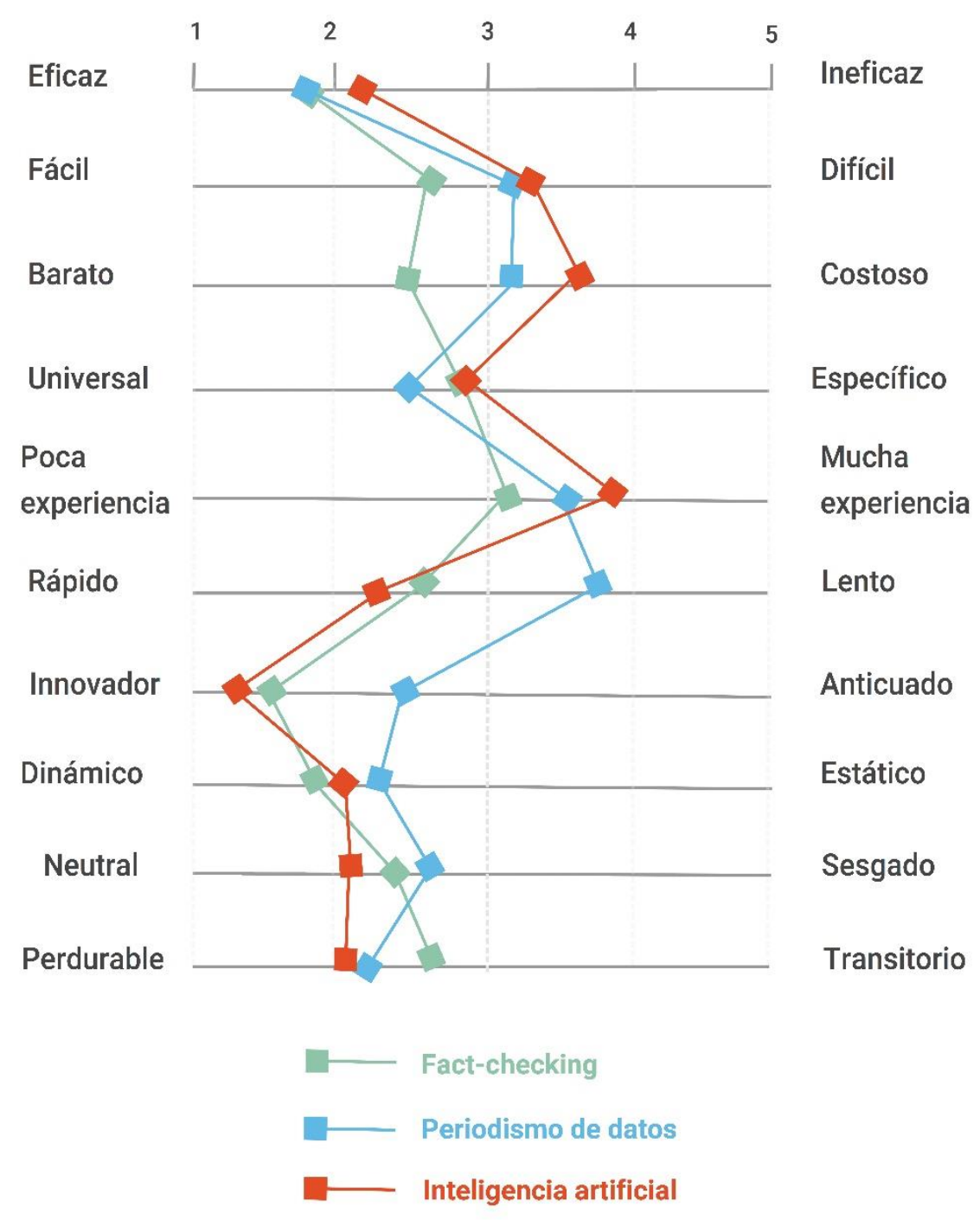

Vivat Academia. Revista de Comunicación. 2021, n 154, 37-63 
Las fake news y los periodistas de la generación z. Soluciones post-millennial contra la desinformación

Figura 2. Perfil del diferencial semántico aplicado sobre periodismo de datos, factchecking e inteligencia artificial

Fuente: elaboración propia

Las comparaciones múltiples entre variables y herramientas a partir de la prueba ANOVA $(F[2,45]=0.64, p=.03)$ y test post hoc mediante prueba HSD Tukey observan diferencias significativas en cuatro de las diez variables analizadas (ver todos los valores en el siguiente enlace: https://cutt.ly/HzExfuH): (1) coste económico, (2) experiencia requerida, (3) rapidez de respuesta y (4) innovación. La inteligencia artificial se considera significativamente más costosa en términos económicos que el fact-checking $(\mathrm{p}<0,01)$ y que el periodismo de datos $(\mathrm{p}=0,026)$. Los participantes en el estudio manifiestan que se requiere una experiencia significativamente mayor a la hora de utilizar instrumentos de inteligencia artificial frente a los requerimientos que demanda el fact-checking ( $\mathrm{p}<0,01$ ), mientras que el periodismo de datos se considera significativamente más lento en su respuesta ante la desinformación que el factchecking $(\mathrm{p}<0,01)$ y que la inteligencia artificial $(\mathrm{p}<0,01)$. Finalmente, el periodismo de datos es percibido como una práctica mucho menos innovadora en la lucha contra esta problemática que los otros dos instrumentos ( $\mathrm{p}<0,01$ en ambos casos).

\section{DISCUSIÓN Y CONCLUSIONES. HACIA UN TECNOCENTRISMO INTEGRADOR}

De acuerdo con los resultados de nuestra investigación, la aproximación al fenómeno de la desinformación desde la óptica de los jóvenes periodistas integra dos visiones complementarias: de un lado, un evidente determinismo tecnológico y, de otro, una perspectiva tradicionalista que sigue colocando los viejos valores del periodismo como factores esenciales para combatir los desórdenes informativos que proliferan en la actualidad. Perciben que la falta de credibilidad de las organizaciones periodísticas tradicionales también constituye una causa a tener en cuenta en la explicación del fenómeno y, por ello, destacan el papel de las instituciones mediáticas como parte de la solución. Una solución que se basaría en el aumento del rigor, la ética y la calidad del trabajo periodístico, la adopción de modelos de comunicación con las audiencias bajo principios más bidireccionales a fin de recuperar la credibilidad perdida, y un mayor pluralismo ideológico en las líneas editoriales para luchar contra los sesgos del propio medio y de sus públicos.

Este tecnocentrismo integrador que fusiona los principios tecnoutópicos con los fundamentos clásicos del periodismo se substancia en la valoración de los instrumentos que en los últimos años se han implementado para detectar y combatir las fake news desde los medios de comunicación (periodismo de datos, fact-checking y uso de la inteligencia artificial), ampliamente aludidos por los participantes en nuestro estudio. El periodismo de datos, que fusiona saberes y prácticas del periodismo tradicional con nuevos instrumentos de recogida, tratamiento y visualización de datos, se percibe como una solución más eficaz que el fact-checking y la inteligencia artificial, a pesar de que estas dos últimas prácticas se consideran más rápidas para confrontar

Vivat Academia. Revista de Comunicación. 2021, nº 154, 37-63 
el problema. Se infiere, por tanto, que la calidad en la lucha contra la desinformación debe prevalecer frente a soluciones que pueden resultar más inmediatas pero que no necesariamente son percibidas como las más eficientes. También es relevante la visión de la inteligencia artificial (la herramienta más tecnológica de las tres) como un instrumento menos sesgado que el periodismo de datos y el fact-checking. Los periodistas de la Generación Z evidencian aquí una cierta tendencia tecnoutópica al olvidar que el diseño de toda solución tecnológica lleva impresos los valores de sus creadores.

Los individuos pertenecientes a esta generación se caracterizan, desde el punto de vista socio-cognitivo, por su deseo de inmediatez y de interacción continua, se conciben a sí mismos como expertos y competentes en TIC y atribuyen expectativas muy elevadas a la tecnología (Bennett et ál, 2008; Gallardo, 2012; Fernández y Fernández, 2016). Además, mantienen una clara preferencia hacia la información visual y presentan un fácil desenvolvimiento en entornos digitales y visuales con una clara tendencia hacia el musltitastking, es decir la gestión de múltiples tareas al mismo tiempo (Cassany y Atalaya, 2008; Reig y Vilchez, 2013). No es de extrañar, por tanto, que evidencien una percepción optimista hacia las posibilidades que ofrecen las herramientas tecnológicas como solución contra la desinformación, dado el contexto en el que esta generación ha nacido y se ha formado. Más bien resulta hasta cierto punto sorprendente la combinación de esta visión celebradora de la tecnología con los viejos valores del periodismo, lo que podría indicar una cierta efectividad de las facultades de Comunicación a la hora de transmitir esta mirada tradicionalista y de respeto hacia los fundamentos éticos propios de la profesión periodística.

Atención especial merece la asunción de una labor didáctica por parte de los medios para formar a la población en la detección de la desinformación. Para los periodistas de la Generación $Z$ entrevistados, es necesaria una potenciación de la educación digital, mediática y crítica tanto de los profesionales de la información como de la sociedad en general. Esta percepción conecta con los resultados de numerosos estudios que han demostrado la incapacidad de los públicos para diferenciar las informaciones falsas de los contenidos verídicos, sobre todo en periodos electorales (Breakstone et ál., 2019). Múltiples investigaciones amplían esta visión aludiendo a un posible sesgo ideológico a la hora de otorgar credibilidad a los contenidos falsos, de forma que aquellos ciudadanos que se definen como conservadores tienden a percibir a los medios tradicionales como menos fiables y a adoptar como creíbles informaciones no verídicas procedentes de las redes sociales (Benkler, Faris y Roberts, 2018). En este marco, una educación crítica de la ciudadanía hacia los contenidos que consume es señalada por nuestros entrevistados como un complemento esencial de la capacitación digital (de carácter más instrumental) para distinguir la verdad de la falsedad. El discurso didáctico de los entrevistados adolece, no obstante, de falta de concreción en las metodologías y estrategias a adoptar.

Finalmente, es reseñable la escasez de referencias a determinados actores que pueden influir en la generación y propagación de desinformación, tales como los propios monopolios informativos y los gobiernos o conglomerados empresariales

Vivat Academia. Revista de Comunicación. 2021, nº 154, 37-63 
cuyas campañas de manipulación y control de la información facilitan una representación tergiversada de la realidad, en ocasiones promovida desde los medios tradicionales que observan el potencial económico de la difusión de contenidos de dudosa calidad y veracidad (Sánchez-Gey Valenzuela, 2019). Se percibe en el discurso de los jóvenes periodistas, por tanto, una mayor atención hacia las plataformas -los espacios tecnológicos- donde circula la desinformación que hacia los actores que la promueven.

Este estudio ofrece un primer acercamiento, un mapa inicial, de las representaciones sociales y percepciones de los jóvenes periodistas sobre la desinformación, uno de los mayores retos que tendrán que afrontar durante su carrera profesional, ya que se prevé que este fenómeno no va a ser resuelto en el corto plazo. Constituye un estudio exploratorio cuyos resultados deberán ser contrastados y ampliados con futuras investigaciones que, desde una mirada cuantitativa, determinen de manera más granular y precisa la adhesión de este colectivo a las dimensiones aquí establecidas. Asimismo, resulta interesante profundizar con muestras más amplias la visión que los nuevos comunicadores tienen sobre los instrumentos y prácticas periodísticas aquí analizados, así como comparar sus percepciones generales sobre el fenómeno de la desinformación y las fake news con las de periodistas experimentados. Conocer cuáles son los paradigmas conceptuales que los profesionales de la comunicación tienen alrededor de esta problemática e identificar cuáles son sus percepciones sobre sus causas y posibles soluciones constituyen aspectos fundamentales para vislumbrar cuál será el papel del periodismo en los próximos años en la lucha contra la desinformación.

\section{REFERENCIAS}

Aleixandre-Benavent, R., Castelló-Cogollos, L. y Valderrama-Zurián, J. C. (2020). Infodemia, desinformación y papel de los profesionales de la información. Profesional de la información, 29(4), e290408. https://doi.org/10.3145/epi.2020.jul.08

Andreu-Sánchez, C., \& Martín-Pascual, M. A. (2020). Fake images of the SARS-CoV-2 coronavirus in the communication of information at the beginning of the first Covid-19 pandemic. El profesional de la información, 29(3), e290309. https:// doi.org/10.3145/epi.2020.may.09

Amrita, M. (2017). Understanding the plague of fake news and how to combat it. Medium. Recuperado de: https://bit.ly/2JoPGSp

Aparici, R. y García-Marín, D. (2019). La posverdad. Una cartografía de los medios, las redes y la política. Gedisa.

Ball, J. (2017). Post-truth: How bullshit conquered the world. Biteback Publishing.

Benkler, Y., Faris, R., \& Roberts, H. (2018). Network propaganda: Manipulation, disinformation, and radicalization in American politics. Oxford University Press.

Vivat Academia. Revista de Comunicación. 2021, n 154, 37-63 
Las fake news y los periodistas de la generación z. Soluciones post-millennial contra la desinformación

Bennett, S., Maton, K., \& Kervin, L. (2008). The Digital Natives Debate: A Critical Review of the Evidence. British Journal of Edu-cational Technology, 39(5), 775-786. http://doi:10.1111/-j.1467-8535.2007.00793.x

Blanco-Herrero, D. y Arcila-Calderón, C. (2019). Deontología y noticias falsas: estudio de las percepciones de periodistas españoles. El profesional de la información, 28(3), e280308. https://doi.org/10.3145/epi.2019.may.08

Brandtzaeg, P. B., Følstad, A., \& Chaparro-Domínguez, M. A. (2018). How journalists and social media users perceive online fact-checking and verification services. $\begin{array}{llr}\text { Journalism } \quad \text { practice, 1109-1129. } & \text { 12(9), }\end{array}$ https://doi.org/10.1080/17512786.2017.1363657

Breakstone, J., Smith, M., \& Wineburg, S. (2019). Students' civic online reasoning: A national portrait. Standford Digital Repository. https://stanford.io/33pvcjY

Brennen J. S., Simón, F., Howard, P. N., \& Kleis-Nielsen, R. (2020). Types, sources, and claims of Covid-19 misinformation. Reuters Institute. https:/ / reutersinstitute.politics.ox.ac.uk/types-sources-and-claims-covid-19$\underline{\text { misinformation }}$

Callejo, J. y Viedma, A. (2005). Proyectos y estrategias de investigación social: la perspectiva de la intervención. Mc Graw Hill/Interamericana de España

Cassany, D., \& Ayala, G. (2008). Nativos e inmigrantes digitales en la escuela. CEE, Participación Educativa, 9, 53-71.

Corbetta, P. (2007). Metodologías y técnicas de investigación social. Mc Graw Hill/Interamericana de España

Corner, J. (2017). Fake news, post-truth and media-political change. Media, Culture and Society, 39(7), 1100-1107. https://doi.org/10.1177/0163443717726743

D’Ancona, M. (2017). Post-truth. The new war on truth and how to fight back. Ebury Press

Dahlgren, P. (2018). Media, knowledge and trust: The deepening epistemic crisis of democracy. $\quad$ Javnost-The 20-27. https://doi.org/10.1080/13183222.2018.1418819

Davies, W. (2016). The age of post-truth politics. The New York Times. https://www.nytimes.com/2016/08/24/opinion/campaign-stops/the-age-ofpost-truth-politics.html 
García-Marín, D.

Las fake news y los periodistas de la generación z. Soluciones post-millennial contra la desinformación

DiFranzo, D. \& Gloria-García, K. (2017). Filter bubbles and fake news. XRDS: Crossroads, The ACM Mafazine for Students, 23(3), 32-35. https://doi.org/10.1145/3055153

Elías, C., \& Catalan-Matamoros, D. (2020). Coronavirus in Spain: Fear of 'official'fake news boosts WhatsApp and alternative sources. Media and Communication, 8(2), 462466. http://dx.doi.org/10.17645/mac.v8i2.3217

Fernández, F. J. y Fernández, M. J. (2016). Los docentes de la Generación Z y sus competencias digitales. Comunicar, 46, 97-105. http://dx.doi.org/10.3916/C46$\underline{2016-10}$

Frías-Navarro, D. (2019). Apuntes de consistencia interna de las puntuaciones de un instrumento de medida. Universidad de Valencia. https://www.uv.es/friasnav/AlfaCronbach.pdf

Fuller, S. (2018). Post-truth: Knowledge as a power game. Anthem Press.

Gallardo, E. (2012). Hablemos de estudiantes digitales y no de nativos digitales. UT, Revista de Ciències de l Educació, 7-21.

Gallotti, R., Valle, F., Castaldo, N., Sacco, P., \& De Domenico, M. (2020). Assessing the risks of 'infodemics' in response to Covid-19 epidemics. MedRxiv. https://doi.org/10.1101/2020.04.08.20057968

García-Marín. D. (2020). Infodemia global. Desórdenes informativos, narrativas fake y fact-checking en la crisis de la Covid-19. Profesional de la información, 29(4), e290411. https://doi.org/10.3145/epi.2020.jul.11

Graves, L. (2016). Deciding what's true. The rise of political fact-checking in American journalism. Columbia University.

Guo, L., \& Vargo, C. (2018). Fake news and emerging online media ecosystem: an integrated intermedia agenda-setting analysis of the 2016 U.S. Presidential Election. Communication Research, 47(2), 1-23. http://dx.doi.org/10.1177/0093650218777177

Heathman, A. (2018). If fake news is a disease, this Bad News game wants to be the vaccination. Evening Standard. https://bit.ly/3qbfbrg

Higdon, N. (2020). The anatomy of fake news. University of California Press.

Hunt, E. (2016). What is fake news? How to spot it and what you can do to stop it. The Guardian. https://bit.ly/3nVNcKu

Iosifidis P., \& Nicoli N. (2020). Digital Democracy, Social Media and Disinformation. Routledge. 
García-Marín, D.

Las fake news y los periodistas de la generación $z$. Soluciones post-millennial contra la desinformación

Kakutani, M. (2018). The death of truth: Notes on falsehood in the age of Trump. Tim Duggans Books.

Keyes, R. (2004). The post-truth era: Dishonesty and deception in contemporary life. St. Martin's Press.

Kucharski, A. (2016). Post-truth: Study epidemiology of fake news. Nature, 540(7634), 525-525. https://doi.org/10.1038/540525a

Lewandowsky, S., Ecker, U. K. H., \& Cook, J. (2017). Beyond Misinformation: Understanding and Coping with the "Post-Truth" Era. Journal of Applied Research in Memory and Cognition, 6(4), 353-369. https://doi.org/10.1016/j.jarmac.2017.07.008

Masip, P., Suau, J. y Ruiz-Caballero, C. (2020). Percepciones sobre medios de comunicación y desinformación: ideología y polarización en el sistema mediático español. Profesional de la información 29(5), e290527. https://doi.org/10.3145/epi.2020.sep.27

Mendiguren, T., Pérez Dasilva, J. y Meso Ayerdi, K. (2020). Actitud ante las Fake News: Estudio del caso de los estudiantes de la Universidad del País Vasco. Revista De Comunicación, 19(1), 171-184. https://doi.org/10.26441/RC19.1-2020-A10

McIntyre, L. (2018). Post-truth. MIT Press.

McNair, B. (2018). Fake news. Falsehood, fabrication and fantasy in journalism. Routledge.

Murolo, L. (2019). La posverdad es mentira. Un aporte conceptual sobre fake news y periodismo. En: R. Aparici y D. García-Marín (Coords.), La posverdad. Una cartografía de los medios, las redes y la política (65-80). Gedisa.

Pérez-Dasilva, J., Meso-Ayerdi, K. y Mendiguren-Galdospín, T. (2020). Fake news y coronavirus: detección de los principales actores y tendencias a través del análisis de las conversaciones en Twitter. El profesional de la información, 29(3), e290308. https://doi.org/10.3145/epi.2020.may.08

Peters, M. A., Jandric, P. \& McLaren, P. (2020). Viral modernity? Epidemics, infodemics, and the bioinformatioonal paradigm. Educatioonal philosophy and theory. https://doi.org/10.1080/00131857.2020.1744226

Rawlinson, K. (2017). Fake news is killing people's minds, says Apple boss Tim Cook. The Telegraph. https://bit.ly/3lf2EzD

Reig, D. y Vilchez, L. (2013). Los jóvenes en la era de la hiperconectividad: tendencias, claves y miradas. Fundación Telefónica. 
García-Marín, D.

Las fake news y los periodistas de la generación z. Soluciones post-millennial contra la desinformación

Rubin, V. L. (2019). The disinformation triangle. The epidemiology of "fake news". Journal of Documentation, 75(5), 1013-1034. https://doi.org/10.1108/JD-12-2018$\underline{0209}$

Salaverría, R., Buslón, N., López-Pan, F., León, B., López-Goñi, I. y Erviti, M. C. (2020). Desinformación en tiempos de pandemia: tipología de los bulos sobre la Covid-19. El profesional de la información, 29(3), e290315. https://doi.org/10.3145/epi.2020.may.15

Sambrook, R. (2018). Fake news week. Three stories that reveal the extreme pressure journalism is now under. The Conversation. https://bit.ly/3ldpG9X

Sánchez-Duarte, J. M. y Magallón-Rosa, R. (2020). Infodemia y COVID-19. Evolución y viralización de informaciones falsas en España. Revista Española de Comunicación en Salud, 31-41. https://doi.org/10.20318/recs.2020.5417

Sánchez-Gey Valenzuela, N. (2019). False news and the work of information professionals in the coverage of events. IROCAMM: International Review of $\begin{array}{llll}\text { Communication and Marketing } & \text { 2(1), }\end{array}$ http://dx.doi.org/10.12795/IROCAMM.2019.v02.i01.07

Schinkel, W. (2008). Contexts of anxiety: The moral panic over "senseless violence" in the Netherlands. Current Sociology, 56(5), 735-756. http:/ /dx.doi.org/10.1177/0011392108093833

Seemiler, C., \& Grace, M. (2016). Generation Z Goes to College. Jossey-Bass.

Silverman, C. (2017). What do we mean when we say fake news? The Fake Newsletter. https://bit.ly/39nh12v

Singh, A. P., \& Dangmei, J. (2016). Understanding the Generation Z: The Future Workforce. South-Asian Journal of Multidisciplinary Studies, 3(3), 1-5.

Stelter, B. (2016). The plague of fake news is getting worse: Here's how to protect yourself. CNN Media. https://cnn.it/2KOl4e0

Suiter, J. (2016). Post-truth politics. Political insight, 7(3), 25-27. https://doi.org/10.1177/2041905816680417

Thurston, I. (2018). Everything is permitted, restrictions still aplly: A psychoanalytic perspective on social dislocation, narcissism, and post truth. Routledge.

Tracy, S. J. (2020). Qualitative research methods. Wiley-Blackwell.

Turner, A. (2015). Generation Z: Technology and Social Interest. The Journal of Individual Psychology, 71(2), 103-113. 
García-Marín, D.

Las fake news y los periodistas de la generación z. Soluciones post-millennial contra la desinformación

Vosoughi, S., Roy, D. \& Aral, S. (2018). The spread of true and false news online. Science, 359(March), 1146-1151. https://doi.org/10.1126/science.aap9559

Wooley, S. (2020). The Reality Game: How the Next Wave of Technology Will Break the Truth and What We Can Do About It. Endevour.

Woollacott, E. (2016). In today's post-factual politics. Google's fact-check tag may not be much help.

Forbes.

https:// www.forbes.com/sites/emmawoollacott/2016/10/14/in-todays-postfactual-politics-googles-fact-check-tag-may-not-be-much-help/

\section{AUTOR/ES:}

\section{David García-Marín}

Doctor por la UNED. Profesor Ayudante Doctor en el Departamento de Ciencias de la Comunicación y Sociología de la Universidad Rey Juan Carlos (Madrid, España), donde imparte la asignatura Nuevas Tecnologías y Sociedad de la Información. En paralelo, ejerce como profesor invitado en diversos másteres en comunicación digital, nuevas pedagogías y periodismo transmedia en la UNED, donde además ha dirigido varios cursos sobre medios digitales y desinformación. Sus áreas de investigación se centran en el podcasting y el audio digital, la desinformación, el periodismo transmedia y la inteligencia artificial aplicada a la comunicación mediática. Es autor de numerosos artículos y libros centrados en las perspectivas actuales de la comunicación y el desafío de la desinformación en la sociedad actual. Su último libro publicado es La posverdad. Una cartografía de los medios, las redes y la política (Gedisa, 2019).

david.garciam@urjc.es

Orcid ID: https:/ / orcid.org/0000-0002-4575-1911

Google Scholar: https://scholar.google.es/citations?user=DjgRxL4AAAAJ\&hl=es

ResearchGate: https://www.researchgate.net/profile/David_Garcia-Marin 